\title{
Análise da comunicação em uma instituição de ensino superior localizada no Estado
}

\section{de São Paulo}

\author{
Analysis of communication in a higher education institution located in the State of São Paulo \\ Análisis de la comunicación en una institución de educación superior ubicada en el Estado de São
}

Paulo

Recebido: 31/12/2020 | Revisado: 01/01/2021 | Aceito: 06/01/2021 | Publicado: 08/01/2021

Leandro Carvalho Bassotto

ORCID: https://orcid.org/0000-0002-0508-9177 Universidade Federal de Lavras, Brasil E-mail: bassotto.lc@gmail.com

Ana Luiza Cordeiro Pereira

ORCID: https://orcid.org/0000-0002-7178-6552 Universidade Federal de Lavras, Brasil

E-mail: analuizacordeiro96@gmail.com

Fernando Ferrari Putti

ORCID: https://orcid.org/ 0000-0002-0555-9271

Universidade Estadual Paulista, Brasil

E-mail: fernando.putti@unesp.br

\begin{abstract}
Resumo
A criação de uma identidade de comunicação nas organizações permite a discussão de abordagens de cunho econômico e/ou administrativo, e por conseguinte, o alcance de vantagens competitivas. Quando considerado o contexto das Instituições de Ensino Superior e a crescente preocupação com seu desenvolvimento e avaliação, passa-se a valorar sua comunicação com os stakeholders. Nesse sentido, este estudo adotou como objetivo analisar, com base na visão de colaboradores, a comunicação interna e externa de uma Instituição de Ensino Superior do estado de São Paulo, com ênfase na criação de vantagem competitiva. Foi elaborado um questionário eletrônico estruturado, o qual foi encaminhado para todos os profissionais de uma Instituição de Ensino Superior localizada no interior paulista, obtendose 32 participações. Os resultados evidenciaram que a comunicação se mostra como um elo que mantém a Instituição de Ensino Superior conectada com seus colaboradores e com o ambiente externo. Além disso, identificou-se a existência de componentes que podem interferir na comunicação interna e externa da organização.
\end{abstract}

Palavras-chave: Educação; Comunicação interna; Comunicação externa; Cultura organizacional.

\begin{abstract}
The communication identity creation in organizations allows economic and / or administrative approaches discussion, and therefore, achievement of competitive advantages. When considering the Higher Education Institutions context and the growing concern with their development and assessment, their communication with stakeholders is valued. In this sense, this study aimed to analyze, based on the employee's view, the internal and external communication of a Higher Education Institution in São Paulo, with an emphasis on creating competitive advantage. A structured electronic questionnaire was prepared, which was sent to all professionals at a Higher Education Institution located in São Paulo interior, obtaining 32 participations. The results showed that communication is a link that keeps the Higher Education Institution connected with its collaborators and with the external environment. In addition, components that could interfere with the organization's internal and external communication was identified.
\end{abstract}

Keywords: Education; Internal communication; External communication; Organizational culture.

\section{Resumen}

La creación de una identidad comunicativa en las organizaciones permite la discusión de enfoques de carácter económico y / o administrativo y, por tanto, la consecución de ventajas competitivas. Al considerar el contexto de las Instituciones de Educación Superior y la creciente preocupación por su desarrollo y evaluación, comienzan a valorar su comunicación con los grupos de interés. En este sentido, este estudio adoptó el objetivo de analizar, a partir de la visión de los empleados, la comunicación interna y externa de una Institución de Educación Superior en el estado de São Paulo, con énfasis en la creación de ventaja competitiva. Se elaboró un cuestionario electrónico estructurado, que se envió a todos los profesionales de una Institución de Educación Superior ubicada en el interior de São Paulo, obteniendo 32 participaciones. Los resultados mostraron que la comunicación es un vínculo que mantiene a la Institución de Educación 
Superior conectada con sus colaboradores y con el entorno externo. Además, se identificó la existencia de componentes que podrían interferir con la comunicación interna y externa de la organización.

Palabras clave: Educación; Comunicación interna; Comunicacion externa; Cultura de la organización.

\section{Introdução}

Segundo Gomes (2016), o ambiente social representa um complexo de relacionamentos entre os agentes e o ambiente capaz de determinar aspectos relacionados ao comportamento de indivíduos sobre diferentes feitios ligados à cooperação. O autor salienta ainda que a comunicação organizacional influencia em diversas questões existentes dentro das empresas, gerando a tensão organização/ambiente. Tal percepção ocorre pela visão proposta por Seidl e Becker (2006), que definem empresa como um ambiente socialmente desenvolvido, que se diferenciando de outras organizações por ser um sistema social criado a partir da comunicação, em suas diversas formas.

Assim, por se tratar de um processo que se relaciona diretamente com o ambiente interno e externo das organizações, cria-se uma identidade de comunicação das instituições de ensino superior. Isso permite a discussão de abordagens de cunho econômico e/ou administrativo e, por conseguinte, o alcance de vantagens competitivas (Gomes, 2016). Na educação superior, a comunicação é um elemento de fundamental importância, por estimular o convívio entre diferentes autores no que tange questões ligadas tanto o processo gerencial quanto às práticas de ensino (Bezerra et al., 2020).

A preocupação com o desenvolvimento e a avaliação de Instituições de Ensino Superior em todo o mundo vem sofrendo aumento nos últimos anos. Essa condição exige cada vez mais envolvimento das organizações educacionais no que se refere à comunicação com todos os tipos de agentes envolvidos, entre eles estudantes, colaboradores e fornecedores (Frederico-Ferreira et al., 2017).

Tal preocupação se deve, segundo Cassundé et al. (2017), ao crescimento exponencial do número de Instituições de Ensino Superior (IES) em outros países, que atualmente se faz presente também no Brasil. Os autores consideram esse aumento uma revolução que propõe mudanças nos sistemas de graduação e pós-graduação, refletindo em modificações estruturais e na cultura de trabalho dessas organizações como componente fundamental para se diferenciar no mercado.

Nunes et al. (2017) reforçam essa ideia ao dizerem que, com a ampliação das IES no país na última década, sistemas de avaliação institucional são fundamentais para incentivar a busca por novos mecanismos de viabilidade, ampliação e melhoria das políticas institucionais, tanto em IES públicas quanto privadas. A discussão no campo educacional sobre questões gerenciais, avaliação, financiamento, dentre outras, tem-se mostrado relevante para as instituições formadoras que devem buscar modificar seu ambiente interno para se adaptarem às novas realidades contemporâneas (Moreira; Iulianelli, 2017).

Avaliações de organizações são importantes ferramentas que permitem aferir comportamentos das IES e verificar falhas e melhorias dessas instituições. Segundo Veludo de Oliveira et al. (2014), conflitos entre os diversos agentes envolvidos nas relações com as IES refletem no distanciamento entre as condições ideais e a realidade, denominadas pelos autores respectivamente como discurso e prática.

A comunicação nas organizações expressa a popularização da educação superior, antes privada a uma elite polarizada, fazendo com que as IES`s se mantivessem distantes da sociedade (Brocco, 2017). Com a popularização da internet, ferramentas de comunicação empresarial se tornaram de fácil acesso (Malizia, 2012). Isso resultou em melhorias em diversos setores organizacionais, influenciando inclusive o ambiente em que a empresa está inserida. Esses avanços se dão por meio do incremento do nível de desenvolvimento socioeconômico, a partir de procedimentos que combinam elementos influentes (emissor, receptor e eventuais ruídos) sobre a comunicação organizacional das empresas (Rodrigues; Matos; Ferreira, 2017).

Aguiar e Mendes (2016) complementam ao dizer que a comunicação se desenvolve significativamente dentro do ambiente organizacional e participa ativamente da gestão institucional, provendo avanços nos processos de mudanças e propiciando melhores resultados no ambiente corporativo. 
O feedback existente no processo e comunicação se torna primordial para estabelecer os parâmetros que garantirão a idoneidade da informação no processo de emissão e recepção entre os agentes e determinará o nível de eficiência da comunicação (Kunsch, 2002). Considerando o atual cenário competitivo em que as organizações estão inseridas, tanto públicas, quanto privadas, faz-se necessária a utilização de estratégias que permitam às empresas se destacarem das demais (Bassotto, 2020). Os Fatores Críticos de Sucesso (FCS), quando identificados, podem ser gerenciados para a melhor utilização dos recursos disponíveis, permitindo desta forma, que a organização adote uma postura estratégica mais adequada em sua gestão.

Desse modo, tem-se a seguinte questão: como é a comunicação interna e externa de uma instituição de ensino superior localizada no estado de São Paulo sob a perspectiva de seus funcionários? A fim de responder tal questionamento, este trabalho tem por objetivo analisar, com base na visão de colaboradores, a comunicação interna e externa de uma Instituição de Ensino Superior (IES) do estado de São Paulo, com ênfase na criação de vantagem competitiva.

Este trabalho se justifica pela importância de se compreender como ocorre a relação entre a universidade e a sociedade. Com efeito, as contribuições com esta pesquisa podem contribuir com o aprofundamento sobre a importância da comunicação para instituições de ensino superior.

\section{Metodologia}

A presente pesquisa possui natureza descritiva com abordagem quantitativa (Pereira et al, 2018). Possui temporalidade transversal, visto que foi realizada no ano de 2017. A escolha dos participantes da pesquisa se deu por meio de uma amostragem não probabilística intencional.

Foi elaborado um questionário eletrônico estruturado, composto por 15 perguntas abertas e fechadas relacionadas à gestão e comunicação em uma instituição de ensino superior do estado de São Paulo. O questionário foi desenvolvido por meio do aplicativo Google Formulário e encaminhado para todos os profissionais da referida instituição de ensino por e-mail, obtendose 32 participações. Conforme citam Fialho, Nunes e Carvalho (2017), questionários eletrônicos são relevantes em pesquisas de opinião por contribuírem com a identificação e (posterior) análise de características específicas existentes na organização.

Os assuntos foram relacionados com as áreas de comunicação, tecnologia da informação (TI), laboratórios, setor responsável pelos estágios acadêmicos, biblioteca, diretoria, estruturas de apoio ao docente, área comercial, serviços de secretaria e a direção. Após as entrevistas, os dados foram analisados pelo software SPSS ${ }^{\circledR}$. Os gráficos foram desenvolvidos com o auxílio de uma planilha eletrônica do Excel $^{\circledR}$.

\section{Resultados e Discussão}

Aproximadamente $31 \%$ dos entrevistados avaliaram a comunicação institucional com a sociedade como ótima; $47 \%$, boa; $19 \%$, regular; e 3\%, ruim. Nenhum dos participantes da pesquisa classificou o nível de comunicação da instituição de ensino superior como péssimo. Na percepção dos colaboradores, a IES possui uma comunicação satisfatória com a sociedade.

Aproximadamente $78 \%$ das pessoas que participaram da pesquisa indicaram perceber as contribuições da IES para o desenvolvimento social da região em que a mesma está inserida. Tal condição indicou uma vantagem competitiva da organização, ao ser reconhecida pela sociedade.

Ao se considerar a comunicação interna da instituição de ensino, foi possível identificar os seguintes resultados: ótima (25\%), boa (44\%), regular (15\%), ruim (16\%) e péssima (0\%). Embora em níveis inferiores à percepção dos colaboradores sobre a comunicação externa, aproximadamente $69 \%$ dos entrevistados identificam aspectos positivos na IES, uma vez que o somatório das avaliações ótima e boa se mostrou como um incentivo ao desenvolvimento interno da comunicação.

Sobre as condições relacionadas à cultura, em que se englobam os sistemas gerenciais da IES, suas metodologias de 
trabalho e aspectos comportamentais ligados aos seus colaboradores, notou-se que $66 \%$ do campo amostral veem tais condições como facilitadoras da atividade comunicativa. Outros $25 \%$ deles se mostraram indiferentes à cultura da instituição, visto que afirmaram que ela não interfere (positiva ou negativamente) nas atividades de comunicação. Apenas $9 \%$ dos entrevistados não souberam opinar e nenhum deles respondeu considerar a cultura da organização como uma condição que aumenta a dificuldade com as atividades relacionadas à comunicação.

Algumas condições de acessibilidade fornecidas pela IES também foram consideradas na pesquisa, como a utilização de e-mail institucional como mecanismo de comunicação. Os resultados indicaram forte aceitação por parte dos colaboradores desses recursos de comunicação fornecido pela instituição de ensino, já que $94 \%$ dos entrevistados responderam utilizar tais serviços de e-mail, enquanto $6 \%$ afirmaram nunca terem utilizado esse recurso. Nessa questão, foram considerados ainda as pessoas que utilizam os serviços de e-mail institucional ocasionalmente (alguns dias da semana) e raramente (poucas vezes ao mês), sendo que, em ambas as opções, nenhuma resposta foi pontuada.

Diante da existência de um recurso presente na instituição de ensino cujo objetivo é divulgar informes semanais com as principais notícias da IES e outras informações relacionadas, aproximadamente $72 \%$ dos integrantes da amostra receberam e leram o informativo, seguidas de aproximadamente $22 \%$ dos entrevistados que receberam semanalmente e leram ocasionalmente. Os entrevistados que conhecem o informativo, mas não o leem e aqueles que não sabem de sua existência representaram $3 \%$ do total de participantes, cada.

Sobre as informações que seriam de maior interesse para os colaboradores, os resultados indicaram que 55\% dos entrevistados disseram desejar receber notícias em geral, $17 \%$ desejam receber notícias de todas as áreas da instituição, $14 \%$ responderam desejar receber informações da reitoria/diretoria e $14 \%$ indicaram o anseio por se informarem por meio de eventos que viessem a ser publicados no informativo. Implica dizer que os colaboradores da IES têm interesse em estar cientes dos acontecimentos em toda a instituição.

Ao serem questionados sobre qual o veículo de comunicação para manter os colaboradores inteirados das notícias da IES, $65 \%$ dos entrevistados demonstraram preferência pelo mecanismo eletrônico e-mail, 28\% pelo portal ou site institucional e $7 \%$ por cartazes e demais informações publicadas em murais da organização.

Quando abordadas as atividades e/ou veículos de comunicação que poderiam ser implementados ou melhorados na faculdade para aperfeiçoamento da comunicação entre os colaboradores, identificou-se a utilização de caixas de sugestões $(18,9 \%)$, reuniões $(13,6 \%)$, eventos, internet e newsletters (10,4\% cada), jornal institucional e mural $(8,3 \%$, cada) e demais opções $(19,7 \%)$. Considerando que nessa questão, cada entrevistado poderia escolher até três opções, foram obtidas 96 referências em 13 opções apresentadas, conforme mostra a Tabela 1. 
Research, Society and Development, v. 10, n. 1, e20510111633, 2021

(CC BY 4.0) | ISSN 2525-3409 | DOI: http://dx.doi.org/10.33448/rsd-v10i1.11633

Tabela 1. Principais meios de comunicação potenciais para melhorar a comunicação interna da Faculdade.

\begin{tabular}{|c|c|c|}
\hline Item & Frequência & $\%$ \\
\hline Caixa de Sugestões & 18 & 18,9 \\
\hline Reuniões & 13 & 13,6 \\
\hline Eventos & 10 & 10,4 \\
\hline Internet & 10 & 10,4 \\
\hline Newsletters & 10 & 10,4 \\
\hline Jornal institucional & 8 & 8,3 \\
\hline Murais & 8 & 8,3 \\
\hline Intranet & 5 & 5,2 \\
\hline Relatórios & 5 & 5,2 \\
\hline Conversas informais & 4 & 4,2 \\
\hline Mala-direta & 3 & 3,1 \\
\hline Correspondência & 1 & 1,0 \\
\hline Outros & 1 & 1,0 \\
\hline Total & 96 & 100,0 \\
\hline
\end{tabular}

Fonte: Dados da pesquisa.

Foi analisada também a necessidade de aperfeiçoamentos para que a comunicação entre os diversos stakeholders da instituição e entre os grupos formados por eles evolua. Os resultados apresentados na Tabela 2 sugerem que as maiores necessidades percebidas pelos participantes da pesquisa foram a existência de jornais e/ou murais, a produção de boletins, jornais e revistas tanto para o público interno como para o público externo, desenvolvimento de atividades de propaganda e publicidade institucional, atendimento ao público e organização de eventos científicos.

Tabela 2. Condições que podem melhorar a comunicação da Faculdade.

\begin{tabular}{lcc}
\multicolumn{1}{c}{ Item } & Frequência & \% \\
\hline Jornais/murais & 11 & 11,6 \\
Produção de boletins, jornais e revistas para público interno e externo & 11 & 11,6 \\
Publicidade e propaganda institucional & 10 & 10 \\
Atendimento ao público (online) & 9 & 10,5 \\
Organização de eventos científicos & 7 & 9,5 \\
Participação em eventos (feiras e exposições) & 7 & 7,4 \\
Programas de visitas à instituição & 6 & 7,4 \\
Elaboração de materiais promocionais (folders, cartazes, etc.) & 6 & 6,3 \\
Produção de press releases & 6 & 6,3 \\
Produção de boletins, jornais e revistas apenas para público externo & 5 & 6,3 \\
Produção de clipping & 5 & 5,3 \\
Contatos com a imprensa & 1 & 5,3 \\
Publicações técnico/científicas & 1 & 1,1 \\
Outros & 95 & 1,1 \\
Total & 50,1 \\
\hline
\end{tabular}

Fonte: Dados da pesquisa.

Quando questionados sobre a principal dificuldade existente na instituição para o desenvolvimento da área de comunicação, os entrevistados indicaram os recursos financeiros $(26,2 \%)$, o nível de compreensão dos dirigentes (18\%) e a definição clara das atribuições de cada departamento da instituição $(14,8 \%)$ como as principais condições limitantes, conforme Tabela 3 . 
Research, Society and Development, v. 10, n. 1, e20510111633, 2021

(CC BY 4.0) | ISSN 2525-3409 | DOI: http://dx.doi.org/10.33448/rsd-v10i1.11633

Tabela 3. Principais limitações existentes dentro da Faculdade.

\begin{tabular}{ccc}
\hline Item & Frequência & \% \\
\hline Recursos financeiros & 16 & 26,2 \\
Nível de compreensão dos dirigentes & 11 & 18,0 \\
Definição clara das atribuições dos departamentos da instituição & 9 & 14,8 \\
Relacionamento com a imprensa & 5 & 8,2 \\
Nível de informação dos colaboradores & 4 & 3 \\
Acesso a novas tecnologias & 3 & 3,6 \\
Relacionamento com os gerentes & 3,9 & 4,9 \\
Obtenção de informações da instituição & 2 & 3,9 \\
Não reconhecimento do trabalho dos colaboradores & 5,3 & 8,2 \\
Outros & 61 & 100,0 \\
\hline Total & & 6 \\
\hline
\end{tabular}

Fonte: Dados da pesquisa.

Foram verificadas dificuldades de comunicação em diversos setores da IES. Os dados apresentados sugerem que a área financeira apresentou maior concentração de citações (23,8\%), seguida pela gestão $(22,4 \%)$, estratégia (13,4\%), publicidade e propaganda $(17,9 \%)$, desenvolvimento tecnológico $(4,5 \%)$, acesso à informação $(4,5 \%)$ e relacionamento interpessoal entre os agentes da organização (7,5\%). Respostas diversas totalizaram 6\% do total de citações. Juntas, as áreas financeiras e gestão da IES compreendem quase a metade de todas as dificuldades de percepção identificadas pelos autores. Tais resultados reforçam a importância de haver uma boa comunicação entre setores mais estratégicos para IES. Bassotto (2020) corrobora com este entendimento e acrescenta que a comunicação em setores mais estratégicos, como os setores financeiro e de gestão, é fundamental para que haja melhor vantagem competitiva em instituições de ensino superior.

A Figura 1 mostra os resultados apresentados e permite identificar a real situação de cada área da IES que deve ser trabalhada e evoluída, cujos piores resultados apresentados se encontram nas extremidades do gráfico e os melhores se aproximam do centro.

Figura 1. Fatores impedidores de crescimento da IES.

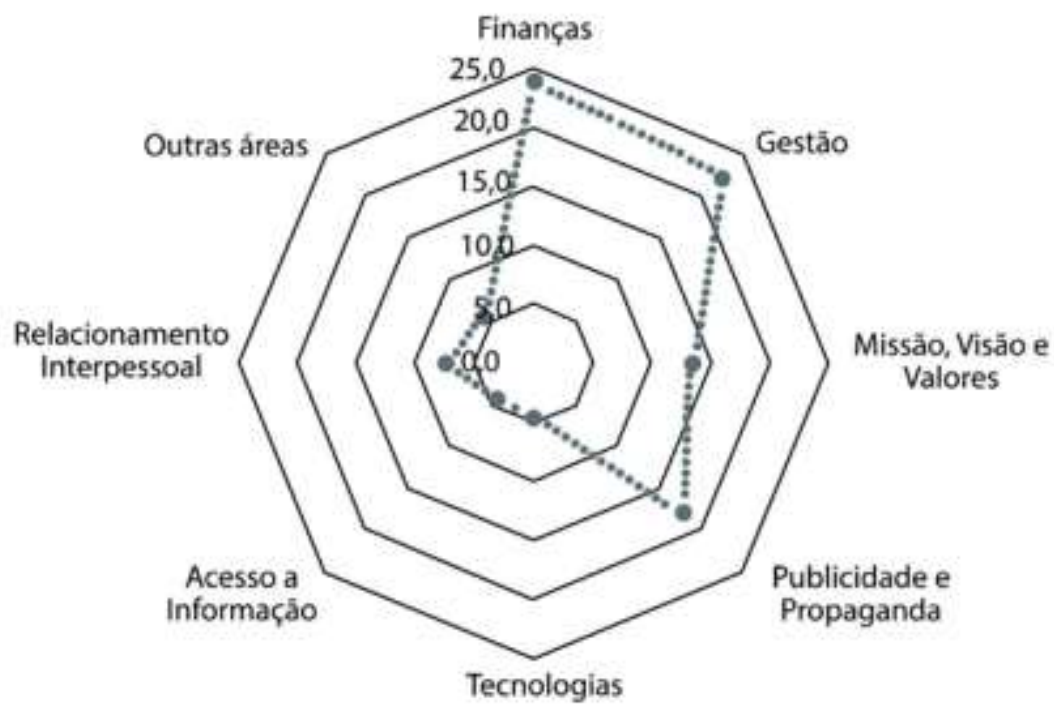

Fonte: Dados da pesquisa.

Os resultados da pesquisa contemplaram também a percepção por parte dos colaboradores sobre as principais áreas 
responsáveis (ou com capacidade potencial) em impulsionar o desenvolvimento da IES. São elas: relacionamento interpessoal (39\%), cultura organizacional (31\%), publicidade e propaganda (17\%) e gestão da instituição (13\%) (Figura 2).

Diante dos resultados apresentados, foi possível confrontar os dados de modo a se analisar a relação existente entre os fatores impulsionadores e limitantes da IES, presentes na Figura 3. As áreas de finanças, utilização de tecnologias, acesso à informação e outras áreas não foram citadas como possuidoras de fatores relevantes de estimulação do desenvolvimento da IES. Contudo, constatou-se que a área de gestão, apesar de apresentar limitações, é vista como um potencial setor no desenvolvimento da instituição de ensino. Análise similar pode ser feita quando se considera a área de publicidade e propaganda. Já a cultura organizacional e a área de relacionamento interpessoal são aquelas mais fortes da IES, uma vez que os fatores impulsionadores do desenvolvimento superaram os fatores impedidores de crescimento da referida instituição.

Figura 2. Comparação dinâmica entre fatores impulsionadores e impedidores de crescimento na IES.

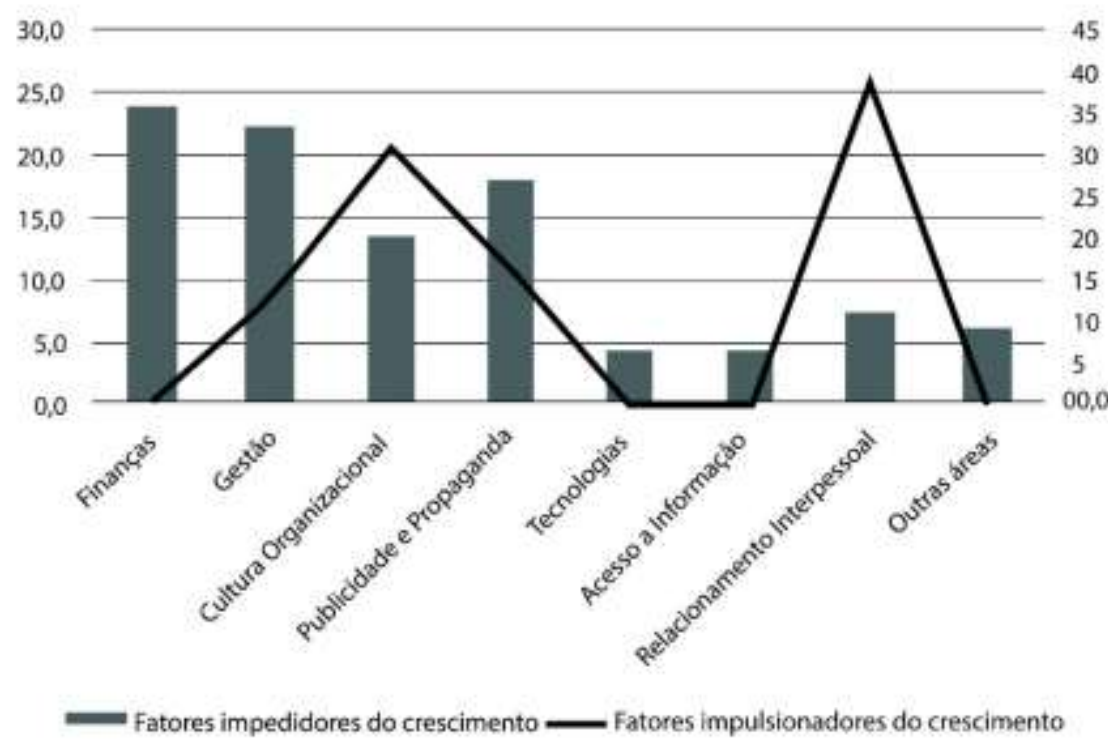

Fonte: Dados da pesquisa.

Diante dos dados apresentados, é possível compreender que a cultura organizacional e o relacionamento interpessoal existentes dentro da IES estudada são os principais constructos que contribuem para a formação e estruturação da comunicação organizacional. Compreender esses conceitos e a forma como as instituições de ensino se posicionam diante da comunicação com seus colaboradores e com a sociedade é fundamental para o desenvolvimento de pesquisas que contribuam com o fortalecimento dessas organizações. Gorgens e Andrade (2020) acrescentam que a comunicação pode ser um importante instrumento de vantagem competitiva para as organizações no futuro.

\section{Conclusão}

Esse estudo permitiu conhecer aspectos de uma Instituição de Ensino Superior sob a ótica dos colaboradores e verificar a existência de fatores limitantes do desenvolvimento da comunicação, que podem eventualmente influenciar negativamente o desenvolvimento institucional. Nesse aspecto, a comunicação se mostrou um importante elo que mantém a IES conectada com seus colaboradores e com o ambiente externo, sendo possível inferir o nível satisfatório de relacionamento com a sociedade existente nessa IES.

Esta pesquisa se limitou a analisar diferentes aspectos da comunicação em uma instituição de ensino superior no estado 
Research, Society and Development, v. 10, n. 1, e20510111633, 2021 (CC BY 4.0) | ISSN 2525-3409 | DOI: http://dx.doi.org/10.33448/rsd-v10i1.11633

de São Paulo. Por se tratar de um estudo de caso, novas pesquisas que explorem a aplicabilidade desses conceitos em diferentes perspectivas podem identificar como é a comunicação interna e externa de IES`s brasileiras. Não obstante, pesquisas que vislumbrem a percepção da comunicação e da importância dos trabalhos desenvolvidos por essas organizações junto à sociedade podem contribuir com o entendimento sobre como os processos de pesquisa, ensino e extensão contribuem com o desenvolvimento social.

\section{Agradecimentos}

Agradecemos à Coordenação de Aperfeiçoamento de Pessoal de Nível Superior (CAPES) e ao Conselho Nacional de Pesquisa (CNPq), bela concessão da Bolsa de Produtividade do primeiro e do último autor (Proc. 303923/2018-0).

\section{Referências}

Aguiar, F. C., \& Mendes, V. L. P. S. (2016). Comunicação organizacional e tecnologias da informação e comunicação (TICs) na gestão hospitalar. Perspectivas em Ciência da Informação, 21(4), 138-155.

Bassotto, L. C. (2020). A comunicação em uma instituição de ensino superior do sul de Minas Gerais: um estudo de caso. Nucleus, 17(2), 439-450.

Bezerra, K. P., et al. (2020). Ensino remoto em universidades públicas estaduais: o futuro que se faz presente. Research, Society and Development, 9(9) e359997226.

Brocco, A. K. (2017). “Aqui em casa a educação é muito bem-vinda”: significado do ensino superior para universitários bolsistas. Rev. Bras. Estud. Pedagog., 98(248), 94-109.

Cassunde, F. R. S. A., Mendonca, J. R. C., \& Barbosa, M. A. C. (2017). A influência das condições institucionais no desenvolvimento de competências eletrônicas dos professores para o ensino na EAD: proposição de um modelo analítico. Avaliação (Campinas), 22(2), 469-493,

Fialho, J. F., Nunes, M. S. C., \& Carvalho, T. (2017). A mediação da informação nos grupos de pesquisa e no GT3 dos ENANCIB: espaços de comunicação científica em Ciência da Informação. Em Questão, 23(2), 257-276.

Frederico-Ferreira, M. M., Camarneiro, A. P. F., Loureiro, C. R. E., C. \& Ventura, M. C. A. A. (2017). Tradução e adaptação do questionário de validade das avaliações dos estudantes ao ensino e aos professores. Avaliação (Campinas), 22(2), 458-468.

Gomes, V. M. L. R. (2016). Uma leitura comunicacional da estratégia nas organizações. Galáxia, 33, $226-238$.

Gorgens, P., \& Andrade, P. C. (2020). A educação universitária apoiada pelas tecnologias digitais de informação e comunicação. Revista Eletrônica Científica Ensino Interdisciplinar, 6(17), 267-280.

Malizia, P. (2012). A “telinha particular”. Objetivo e funções da Web TV na Comunicação Organizacional: uma resenha dos estudos recentes. Intercom-Revista Brasileira de Ciências da Comunicação, 35(2), 291-311.

Moreira, L. P., \& Iulianelli, J. A. S. (2017). Formação docente e ensino de política educacional em instituições de educação superior do Rio de Janeiro. Ensaio: Avaliação e Políticas Públicas em Educação, 25(97), 854-873.

Veludo-de-Oliveira, T. M., Aguiar, F. H. O., Queiroz, J. P., \& Barrichello, A. (2014). Cola, plágio e outras práticas acadêmicas desonestas: um estudo quantitativo-descritivo sobre o comportamento de alunos de graduação e pós-graduação da área de negócios. Rev. Adm. Mackenzie, 15 (1), 73-97.

Nunes, E. B. L. de L. P., Duarte, M. M. S. L. T., \& Pereira, I. C. A. (2017). Planejamento e avaliação institucional: um indicador do instrumento de avaliação do SINAES. Avaliação (Campinas), 22(2), 373-3847.

Pereira A. S., et al. (2018). Metodologia da pesquisa científica. Ed. UAB/NTE/UFSM. https://repositorio.ufsm.br/bitstrea $\mathrm{m} /$ handle/1/15824/Lic_Computacao_Metodologia-Pesquisa-Cientifica.pdf?sequence=1.

PMBOK, Guia. (2004). Um guia do conjunto de conhecimentos em gerenciamento de projetos. Project Management Institute.

Seidl, D., \& Becker, K. H. (2006). Organizations as distinction generating and processing systems: Niklas Luhmann's contribution to orga nization studies. Organization Introduction, 13 (1), 9-35.

Rodrigues, E. C., Matos, D. A. S., \& Ferreira, A. dos S. (2017). Nível socioeconômico e ensino superior: cálculo e aplicações. Avaliação: Revista da Avaliação da Educação Superior, 22(2), 494-511. 